\title{
SUPLEMENTAÇÃO DE HORMÔNIO DO CRESCIMENTO OU ZINCO NO CRESCIMENTO DE CRIANÇAS NÃO EUTRÓFICAS: SÍNTESE DE EVIDÊNCIAS PARA TOMADA DE DECISÃ̃ ESTRATÉGICA NA GESTÃ O EM SAÚDE
}

\author{
Supplementation of growth hormone or zinc in growth of non-eutrophic children: synthesis \\ of evidence for a strategic decision health management \\ Clariana Pacci Moreira dos Santos ${ }^{1}$, Vanessa Fernandes Coutinho ${ }^{2}$, Renato Ribeiro \\ Nogueira Ferraz ${ }^{3}$ \\ ${ }^{1-3}$ Universidade Estácio de Sá - SP.
}

\begin{abstract}
RESUMO
A baixa estatura infantil está relacionada a fatores como morbidade, mortalidade, baixa estatura na idade adulta, e estado nutricional, podendo ser causada por influências genéticas ou ambientais. Objetivo: Revisar na literatura acerca das técnicas a suplementação do zinco ou a utilização de hormônio GH no crescimento de crianças, comparando suas vantagens e aplicações. Metodologia: Trata-se de uma revisão da literatura com síntese de evidências, com artigos sobre a comparação entre os efeitos do hormônio do crescimento GH e zinco no crescimento de crianças não eutróficas. Síntese de evidências: ao se comparar a capacidade de ambos os métodos de diferenciação o hormônio GH é um tratamento em longo prazo podendo levar à altura adulta dentro do esperado e a suplementação do zinco atua diretamente no hormônio GH já produzido pela criança obtendo resultados diferentes pois depende da resposta de cada organismo.

Palavras chave: Crianças, Estatura, Suplementação, Zinco, Hormônio do Crescimento, Gestão em Saúde.
\end{abstract}

\begin{abstract}
Child's low height is related to factors such as morbidity, mortality, short stature in adulthood, and nutritional status, and may be caused by genetic or environmental influences. Objective: To review the literature on the techniques of zinc supplementation or the use of GH hormone in the growth of children, comparing their advantages and applications. Methodology: This is a literature review with synthesis of evidence, with four articles on the comparison between the effects of growth hormone GH and zinc on the growth of non-eutrophic children. Synthesis of evidence: when comparing the ability of both differentiation methods the GH hormone is a long-term treatment that can lead to adult height as expected and zinc supplementation acts directly on the GH hormone already produced by the child, obtaining different results because depends on the response of each organism.

Keywords: Children, Growth, Supplementation, Zinc, Growth Hormone, Health Management.

\section{INTRODUÇÃO}

A baixa estatura infantil está relacionada a fatores como morbidade, mortalidade, baixa estatura na idade adulta e estado nutricional, podendo ser causada por influências genéticas ou ambientais. A partir disso a Organização Mundial da Saúde (OMS), e nacionais, como o Ministério da Saúde (MS) e a Sociedade Brasileira de Pediatria (SBP), preconizam
\end{abstract}


o acompanhamento do crescimento como atividade de rotina na atenção à criança (ORLONSKI et al., 2009).

Segundo pesquisas da Pesquisa Nacional sobra Saúde e Nutrição (PNSN) realizadas em 1974, 31\% das crianças brasileiras menores de 5 anos apresentavam alguma forma de desnutrição. O déficit mais frequente aparecia na relação altura/idade, indicando predomínio da desnutrição crônica (SIGULEM; DEVINCENZI; LESSA, 2000). No ano de 2005 aproximadamente 178 milhões de crianças menores de 5 anos em países de baixa e média renda apresentaram baixa estatura. Em 2015 estimaram-se declínios tanto na prevalência da baixa estatura como do baixo peso em crianças (MONTEIRO et al., 2013).

A atenção na saúde e estado nutricional durante o crescimento das crianças é uma medida de prevenção a distúrbios na saúde e nutrição, independentemente de suas etiologias, que podem vir afetar o crescimento infantil. Em países em desenvolvimento grande parte dos problemas de saúde e nutrição durante a primeira fase da vida está relacionada ao consumo alimentar inadequado e ao padrão de vida da população. Dessa forma, então, a avaliação do crescimento infantil é também uma medida indireta da qualidade de vida da população. (2)

Em relação a suplementações na fase da infância onde o crescimento ocorre por divisão celular e requer DNA, RNA e síntese protéica, o zinco participa de uma variedade de processos celulares como co-fator para inúmeras enzimas, com funções catalíticas, estruturais e reguladoras influenciando a expressão gênica por meio de fatores de transcrição (BUENO; CZEPIELEWSKI, 2007). No caso de suplementação de hormônio do crescimento há indícios que o mesmo pode visar melhorias no perfil metabólico das crianças de baixa estatura (1).

Foi observado que na literatura não existe ainda um consenso sobre qual o melhor método no tratamento de tal distúrbio no crescimento. Logo, nota-se a necessidade em revisar a literatura sobre a importância do uso do hormônio do crescimento GH e o zinco, visando o auxílio da classe de nutricionistas para decisão de qual melhor método de suplementação dietética em caso de crianças com baixa estatura.

Em base nos dados, essa revisão tem como objetivo comparar os resultados obtidos por meio de suplementação de hormônio GH e zinco em crianças não eutróficas, visando definir a eficácia da implementação desses tratamentos complementares e contribuir com o direcionamento do nutricionista no processo de escolha da suplementação mais adequada perante diagnóstico.

\section{OBJETIVO}

Revisar na literatura acerca das técnicas a suplementação do zinco ou a utilização de hormônio GH no crescimento de crianças, comparando suas vantagens e aplicações.

\section{MÉTODO}

A revisão de literatura foi sintetizada na linguagem de indexação documental a partir dos seguintes descritores no idioma português: baixa estatura, suplementação de zinco, suplementação de hormônio do crescimento. Estes descritores foram combinados utilizando o operador booleano AND: "suplementação AND crianças", "baixa estatura AND crianças", "suplementação de zinco AND crescimento" e "suplementação de GH AND crianças", com a utilização de uma ferramenta computacional denominada Publish or Perish, que se utiliza do buscador Google Acadêmico para vasculhar as bases de dados de acordo com a estratégia de pesquisa adotada, todavia verificando os coeficientes científicos dos artigos por meio da avaliação de seus fatores de impacto e índice $\mathrm{h}$. Os critérios de inclusão foram artigos de 
todos os anos de publicação, que abordassem o tema proposto e apresentassem índice $h$. Foram excluídos materiais e artigos que não contemplassem a temática proposta pelo estudo. A categorização dos artigos encontrados ocorreu de maneira crescente a partir do índice h e os dados obtidos com esta categorização foram analisados para revisão da literatura e agrupados para síntese de evidências.

\section{RESULTADOS}

A revisão de literatura foi finalizada no dia 25 de fevereiro de 2017. Foram encontrados 18 artigos, dos quais apenas 4 obras foram selecionadas para revisão de literatura após leitura dos títulos e dos resumos desses artigos. Os demais artigos não realizaram a eficácia do tratamento de suplementação do zinco e do hormônio $\mathrm{GH}$, ou envolviam comparação dos mesmos, porém sem diferenciá-las no crescimento de crianças não eutróficas.

\section{REVISÃO DA LITERATURA}

Em relação à suplementação de hormônio GH, Zegher et al. (2000) realizaram um estudo do tratamento contínuo e descontínuo de hormônio $\mathrm{GH}$, onde foram avaliadas em uma análise de quatro estudos independentes dois com cada modalidade de tratamento. As crianças em tratamento contínuo receberam GH na dose de 33 ou $67 \mu \mathrm{g} / \mathrm{kg} / \mathrm{dia}$. Já as em tratamento descontínuo receberam doses mais altas de 67 a $100 \mu \mathrm{g} / \mathrm{kg} /$ dia por dois anos, ficaram, no mínimo, um ano sem tratamento e somente retomavam o tratamento se a altura voltasse a ficar abaixo dos valores recomendados ou se estivessem em puberdade. Foram tratadas quatro crianças a intervalos de três meses com e sem GH. Ao final de seis anos de acompanhamento, o ganho de altura foi similar entre as diferentes modalidades de tratamento. As vantagens do regime descontínuo foram o menor número de injeções e a dose menor de GH por quilo ao final dos seis anos de tratamento, uma vez que as crianças tinham peso mais baixo quando iniciaram o tratamento. Os autores alertam que as crianças com deficiência de GH não devem ser tratadas com o regime descontínuo.

Simon et al. (2006) avaliaram os benefícios do tratamento de suplementação de hormônio GH na dose de $67 \mu \mathrm{g} / \mathrm{kg} / \mathrm{dia}$. As crianças foram acompanhadas durante quatro anos. Um grupo recebendo GH ano sim, ano não. Outro grupo recebeu GH dois anos consecutivos seguidos de dois anos sem GH. Ambos os grupos apresentaram aumento da velocidade de crescimento durante os períodos de tratamento, porém acompanhado de importante diminuição da velocidade de crescimento nos períodos sem GH. Apesar da boa velocidade de crescimento durante o tratamento, a interrupção anual do tratamento não levou a maior ganho de altura. Os autores alertam que a parada do tratamento após a normalização da altura deve ser cuidadosamente avaliada, uma vez que a velocidade de crescimento pode diminuir de maneira significativa prejudicando o ganho final de altura.

Em comparação a suplementação de zinco Alves (2012), analisou o efeito da suplementação de zinco na secreção do hormônio do crescimento $(\mathrm{GH})$ em crianças provenientes de 3 escolas municipais em Natal/RN entre 6 e 9 anos de idade as quais foram suplementadas oralmente com $5 \mathrm{mg} /$ dia de sulfato de zinco durante 3 meses. Os níveis plasmáticos de GH aumentaram durante a administração de zinco, ou seja, houve correlação positiva entre a suplementação com o estímulo do hormônio da própria criança, não necessitando ser suplementado GH.

Rocha (2014) realizou um estudo onde avaliou o efeito da suplementação oral de zinco para o estímulo do crescimento de um grupo experimental de 30 crianças 
aparentemente saudáveis e eutróficas, entre 8 e 9 anos de idade e obteve um resultado significativo em relação ao crescimento dos mesmos pois a suplementação aumentou as concentrações séricas de zinco e as concentrações plasmáticas de $\mathrm{GH}$.

\section{SÍNTESE DE EVIDENCIAS}

A literatura demonstra dados contraditórios em relação à suplementação mais adequada a ser prescrita em caso de crianças com baixa estatura. Porém, demonstra que a especificidade é bastante comparável. Ao se comparar a capacidade de ambos os métodos de diferenciação, o hormônio GH é um tratamento em longo prazo, podendo levar à altura adulta dentro do esperado. A suplementação do zinco atua diretamente no hormônio GH já produzido pela criança, obtendo resultados diferentes, pois depende da resposta de cada organismo. Todavia, novas revisões englobando artigos de bases internacionais são importantes para ajuda na decisão clínica.

\section{REFERÊNCIAS}

ALVES, C. X. et al. Positive effects of zinc supplementation on growth, GH, IGF1, and IGFBP3 in eutrophic children. Journal of Pediatric Endocrinology and Metabolism, v. 25, n. 9-10, p. 881-887, 2012.

BUENO, A. L.; CZEPIELEWSKI, M. A. Micronutrientes envolvidos no crescimento. Rev $H C P A$, v. 27, n. 3, 2007.

DE ZEGHER, F. et al. Growth hormone treatment of short children born small for gestational age: growth responses with continuous and discontinuous regimens over 6 years. The Journal of Clinical Endocrinology \& Metabolism, v. 85, n. 8, p. 2816-2821, 2000.

MONTEIRO, C. A. et al. Desigualdades socioeconômicas na baixa estatura infantil: a experiência brasileira, 1974-2007. Estudos Avançados, v. 27, n. 78, p. 38-49, 2013.

ORLONSKI, S. et al. Estado nutricional e fatores associados ao déficit de estatura em crianças atendidas por uma unidade de ensino básico de tempo integral. Journal of Human Growth and Development, v. 19, n. 1, p. 54-62, 2009.

ROCHA, E. D. DE M. Efeitos da suplementação oral de zinco sobre o crescimento de crianças pré-púberes saudáveis e eutróficas. 2014. Disponível em: <https://repositorio.ufrn.br/jspui/handle/123456789/19528>. Acesso em: 3 set. 2017.

SIGULEM, D. M.; DEVINCENZI, M. U.; LESSA, A. C. Diagnóstico do estado nutricional da criança e do adolescente. J Pediatr, v. 76, n. 3, p. 275-84, 2000.

SIMON, D. et al. Intermittent recombinant growth hormone treatment in short children born small for gestational age: four-year results of a randomized trial of two different treatment regimens. Hormone Research in Paediatrics, v. 66, n. 3, p. 118-123, 2006. 